\title{
Erratum to: Socio-Ecological Predictor Model of Parental Intention to Participate in Triple P-Positive Parenting Program
}

\author{
Yuki Matsumoto $^{1} \cdot$ Kate Sofronoff $^{1} \cdot$ Matthew R. Sanders $^{1}$
}

Published online: 21 March 2015

(c) Springer Science+Business Media New York 2015 Erratum to: J Child Fam Stud (2009) 18:274-283
DOI 10.1007/s10826-008-9227-9

\section{Authors' Statement of Conflict of Interest}

The Triple $\mathrm{P}$-Positive Parenting Program is owned by the University of Queensland. The University through its main technology transfer company, UniQuest Pty Ltd, has licensed Triple P International Pty Ltd to publish and disseminate the program worldwide. Royalties stemming from published Triple $\mathrm{P}$ resources are distributed to the Parenting and Family Support Centre; School of Psychology; Faculty of Health and Behavioural Sciences; and contributory authors. No author has any share or ownership in Triple P International Pty Ltd. Matthew R. Sanders is the founder and an author on various Triple P programs and a consultant to Triple P International.

The online version of the original article can be found under doi:10. 1007/s10826-008-9227-9.

Kate Sofronoff

kate@psy.uq.edu.au

1 School of Psychology, The University of Queensland,

St. Lucia, Brisbane, Australia 